\title{
EFFECTS OF KETAMINE AND HALOTHANE ON NORMAL AND ASTHMATIC SMOOTH MUSCLE OF THE AIRWAY IN GUINEA PIGS*
}

\author{
Alfredo Cabanas, Joseph F. Souhrada and J. Antonio Aldrtete
}

ABSTRACT

\begin{abstract}
In vitro preparations of trachea isolated from normal and asthmatic guinea pigs were used to measure their maximum contractile response to histamine challenge and to determine spontaneous relaxation of smooth muscle of the airway. The effect of ketamine and halothane on these reactions was investigated. The optimal ketamine concentration was found to be $10 \mu \mathrm{g} / \mathrm{ml}$. This dose attenuated the maximum contraction and produced greater relaxation $(p<0.01)$ of isolated trachea. However, ketamine failed to prevent an anaphylactic (SchultzDale) response when antigen (one per cent albumin) was added in an experimental chamber containing pre-sensitized guinea pig trachea. In contrast, halothane abolished any response to histamine challenge and prevented development of the Schultz-Dale response of smooth muscle from the airway of asthmatic guinea pigs.
\end{abstract}

BeCAUSE OF AN APPARENT REDUCTION in airway resistance, ' ketamine $\mathrm{HCl}$ has been proposed as the anaesthetic of choice in patients suffering from bronchial asthma. ${ }^{2}$ However, in spite of this well-studied clinical impression, the precise mechanism of action of ketamine upon smooth muscle of the airway remains unclear. Most investigations in vitro have used helical and/or chain tracheal preparations of normal guinea pigs made acutely asthmatic, ${ }^{3.4}$ which could affect the functional performance of airway smooth muscle.

In this study, we intended to corroborate the previous observations and to compare them with findings using isolated tracheae of chronically sensitized guinea pigs, to more closely simulate asthmatic airways.

\section{Methods}

Tracheal specimens $12 \mathrm{~mm}$ long were obtained from anaesthetized normal guinea pigs weighing

*From the Departments of Anesthesiology and Medicine, University of Colorado School of Medicine and the National Jewish Hospital and Research Center, Denver, Colorado.

Alfredo Cabanas, M.D., Research Fellow in Anesthesiology; Joseph F. Souhrada, M.D., Ph.D., Associate Professor of Medicine, Director, Pulmonary Physiology Laboratory, National Jewish Hospital and Research Center; J. Antonio Aldrete, M.D., M.S., Professor and Chairman, Department of Anesthesiology, University of Colorado School of Medicine, Denver, Colorado, U.S.A.

Address all correspondence to: J. Antonio Aldrete, M.D., M.S., Department of Anesthesiology (B 113), University of Colorado Medical Center, Denver, Colorado, 80262, U.S.A. 47 between 400 and $600 \mathrm{gm}$. Segments of trachea were procured immediately after decapitation and placed in a special tissue chamber with Krebs-Henseleit solution maintained at $37^{\circ} \mathrm{C}$; a gas mixture of 80 per cent nitrogen, 19 per cent oxygen and one per cent carbon dioxide was bubbled through the chamber. One end of the circular scgment was fixed in the tissue chamber, while the other was attached to an isometric force transducer (Grass 0.03 ) and the changes of isometric tension werc displayed on a Beckman recorder (B 611). The tracheal segments were set at $0.5 \mathrm{gm}$ resting tension and allowed to incubate for 75 minutes, as described by Souhrada and Dickey.

The airways of 32 guinea pigs were sensitized, or rendered asthmatic, by the following method: fresh undiluted egg white was injected intraperitoneally for three consecutive days, followed by a period of two weeks to allow for active immunization. The animals were then exposed to an antigen for a period of fifteen seconds every day for the subsequent three weeks, the exposure consisting of direct inhalation of one per cent albumin aerosol administered through a nebulizer while the animals were restricted to a plexiglass chamber. During exposure to the antigen aerosol, some guinea pigs developed dyspnoea, frequently accompanied by wheezing (as observed by auscultation) and coughing; however most of these symptoms subsided within 20 to 25 minutes.

Experiments were conducted with eight segments of tracheae isolated from both asthmatic and normal guinea pigs, with ketamine $(10 \mu \mathrm{g} / \mathrm{ml})$ given before and after histamine challenge. A

Canad. Anaesth. Soc. J., vol, 27, no. 1, January 1980 
EFFECT OF METAMIKE ON THE RELAXATIOH OF AIRWAY SMDOTH MUSCLE
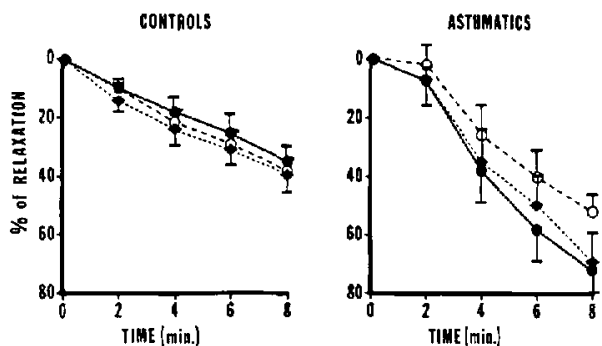

O-.- - O No Trestment

$\longrightarrow$ Kelamine $(10 \mathrm{Ft} / \mathrm{cc})$ after Histamios

- Ketamine $(10 \mathrm{gg} / \mathrm{cc})$ priar lo Histamin

Figurt 1 Alterations of relaxation of tracheal smooth muscle after a maximal contraction in untreated normal and asthmatic guinea pigs. Changes observed when $10 \mu \mathrm{g} / \mathrm{ml}$ of ketamine were added to the preparation before and after histamine challenge are also shown.

histamine dose-response curve was developed in both groups of animals, using negative logarithmic molar doses of histamine. ${ }^{5}$ Similarly, the effects of incremental concentrations of ketamine were observed in tracheae of normal guinea pigs.

Halothane in concentrations of 2 MAC (volumes per cent) was bubbled into the preparations containing specimens from either eight normal or eight asthmatic guinea pigs and their responses to negative logarithmic incremental doses of histamine were observed.

Finally, we studied the ability of both ketamine $(10 \mu \mathrm{g} / \mathrm{ml})$ and halothane $(2 \mathrm{MAC})$ to alter the Schultz-Dale response, which is considered an anaphylactic reaction elicited by adding one per cent egg white to eight preparations containing already sensitized tracheae for each of the anaesthetics. Recordings were obtained in every case, and the results analyzed by Student's t-test.

\section{RESULTS}

The changes in the rate of relaxation after a maximal contraction in untreated normal and asthmatic guinea pig tracheae are shown in Figure 1 . Figure $I$ also depicts the changes occurring after ketamine $(10 \mu \mathrm{g} / \mathrm{ml})$ was given either before or after histamine, revealing a decrease in relaxation of about 36 per cent. This occurred in a period of eight minutes and, similarly, the degree of relaxation after a maximum contraction following histamine challenge was not statistically significant between the three groups of normal
HISTAMINE DOSE-RLSPOHSE CURYE OF AIRWAY SMOOTH MUSCLF IN asthmatics (O) ARO COHTROLS (O)
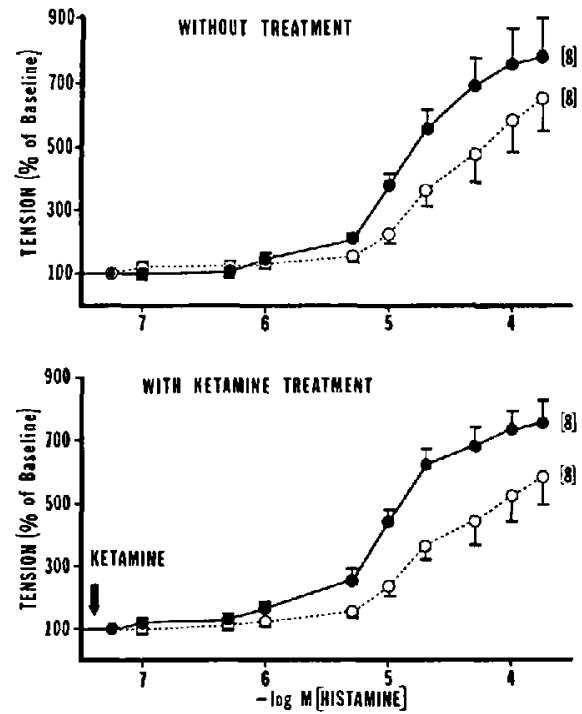

Figure 2 The dose-related response to histamine is depicted in airway smooth muscle of asthmatic and normal guinea pigs. The modification of the same by pretreatment with ketamine is also shown.

EFFECT OF DIIFERENT DOSES OF KETAMINE OH CONTRACILL

AMD RELAXANT RESPONSES OF HORMAL AIRWAY SMOOTH MUSCLE
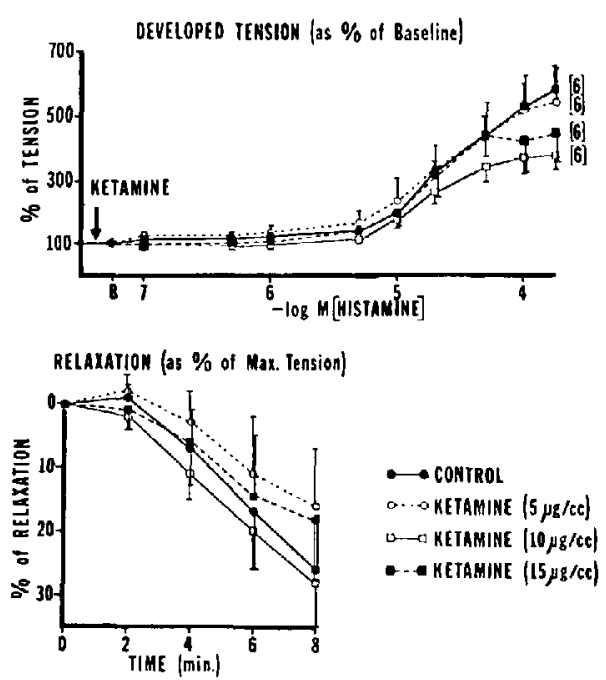

Figure 3 The dose response elicited by ketamine dosages ranging from 5 to $51 \mu \mathrm{g} / \mathrm{ml}$ is shown in percentage of tension developed from base line or percentage of maximal tension developed from baseline. 
EEIECT OF HALOTHANE ON MIRWAY SMOOTH MLSELE

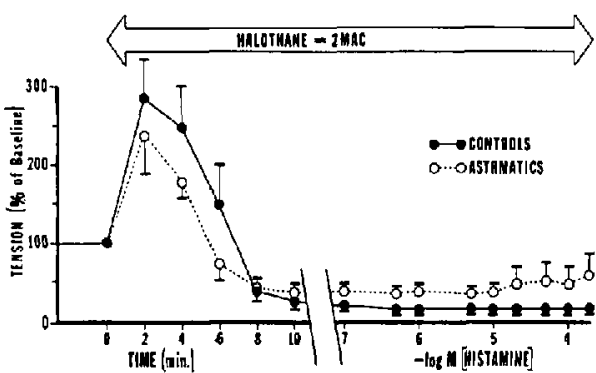

FIGURE 4 Depicts the inhibiting action of halothane on the tension contracture of tracheal smooth muscle produced by negative logarithmic doses of histamine.

animals. A different effect was noted in the presensitized tracheae, with a decrease of relaxation of 55 per cent in the untreated preparations, of 71 per cent when ketamine was given before and of 75 per cent when it was given after a single dose of histamine. There was a statistically significant difference $(p<0.01)$ when the untreated preparations were compared with those receiving ketamine and ketamine plus histamine, but no significant difference was found between the two latter groups.

Incremental doses of histamine produced nearly parallel dose response curves in tension changes of untreated preparations and others receiving ketamine $10 \mu \mathrm{g} / \mathrm{ml}$. No statistical difference was found between the two untreated groups. However, there was a trend toward a slower rise in the asthmatic tracheae when ketamine was given before histamine (Figure 2).

Results from attempts to define the dose of ketamine that would produce the optimal effect in normal airway muscle are shown in Figure 3. They are expressed either as per cent of tension developed from baseline or as per cent of maximal tension with different doses of ketamine. These are interpreted as relaxation correlated with time of observation. In both, the concentration of ketamine in the solution that developed the least tension and the greatest per cent of relaxation was $10 \mu \mathrm{g} / \mathrm{ml}$; hence this concentration appears to produce the optimal result.

The effect of 2 MAC concentration of halothane on the expected response to negative incremental molar doses of histamine is shown in Figure 4 . The blocking action of the anaesthetic against the expected contractile response after histamine is shown when the bronchoconstrictive substance was added in both asthmatic and normal tracheae.
EFIECT Of MITAMIHE AMO HALOTHAHE ON SCHUL12-DALE RESPOHSE

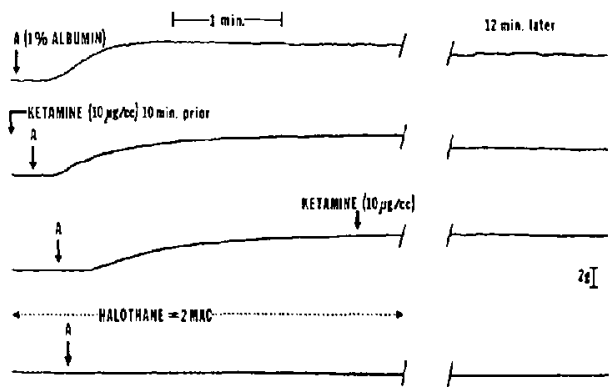

FIGURE 5 Comparison of halothane and ketamine inhibitory effects an the Schultz-Dale response when one per cent albumin was added to the physiological bath containing sensitized tracheas.

Similarly, 2 MAC halothane prevented the occurrence of the Schultz-Dale responses when albumin was injected into the preparation (Figure 5). In contrast, ketamine before or after the albumin failed to alter such a response.

\section{Discussion}

The conflicting reports on the effects of ketamine on airway resistance and its role as an anaesthetic in asthma are probably derived from different clinical observations and in vitro studies.

Corssen and others ${ }^{2.6}$ reported that ketamine relieved bronchospasm for up to 10 minutes in asthmatic patients soon after its administration. They proposed the increased plasma norepinephrine level known to occur during ketamine anaesthesia' as the mediating factor in the decrease in airway resistance observed. However, Stone, el $a l .^{8}$ have raised doubts as to whether norepinephrine per se produces bronchorelaxation.

Another factor contributing to the apparently innocuous action of ketamine in asthmatic patients may be direct partial vagal blockage, as shown by Chodoff; ${ }^{9}$ however, this would be only a palliative benefit and requires the intact subject.

In our study, ketamine appeared to decrease the contractile response of airway smooth muscle isolated from asthmatic guinea pigs, when treacheal preparations were exposed to histamine challenge. Similarly, this anaesthetic agent potentiated relaxation in the tracheae of asthmatic guinea pigs after a maximum contraction was produced by histamine. The findings presented indicate that susceptible airways may respond mildly favourably to the administration 
of ketamine either before or after histamine challenge. This seems to be a direct effect on the smooth muscle of the airway, whether this is independent of systemic influences from sympathomimetic or any other endogenous hormones or neurogenic control. These effects on contractility and relaxation were optimal when the concentration of ketamine was $10 \mu \mathrm{g} / \mathrm{ml}$ in the preparation. Nevertheless, this action appeared to be only moderately effective, since ketamine failed to prevent an anaphylactic reaction, represented by the Schultz-Dale response, when the antigen (albumin) was introduced into the tissue chamber with the tracheal preparation.

Halothane (2 MAC concentration) had a strongly inhibitory effect on histamine challenge in the tracheae of normal as well as asthmatic guinea pigs. Moreover, it completely blocked the Schultz-Dale response. The mechanism of action of halothane is thought to be $\beta$-adrenergic stimulation, as derived by Klide and Aviado, ${ }^{10}$ whose study in dogs revealed a decrease in pulmonary resistance, in turn inhibited by $\beta$-adrenergic blocking drugs.

Similarly, halothane has also been noted to produce an increase in bronchial caliber and in pulmonary compliance, 11.12 as well as minimal change in pulmonary resistance in the intact ${ }^{13}$ and the functionally isolated lung. ${ }^{14}$

Waltemath and Bergman ${ }^{15}$ measured respira. tory resistance and compliance in anaesthetized, intubated patients in whom respiratory resistance was artificially increased by ultrasonic aerosols. Ketamine had no effect on airway resistance, but decreased compliance in subjects with normal or increased respiratory resistance. Halothane, however, caused a prompt decrease in respiratory resistance, without changing compliance. These data are thus compatible with our in virro findings.

The method used in our study utilized tracheae of guinea pigs made chronically asthmatic, which more closely resembles the pathophysiology seen in asthmatic patients than an acute preparation does. The in vitro studies made by Souhrada and Dickey ${ }^{5}$ revealed the effect of acute and chronic experimental asthma on the spontaneous activities of smooth muscle of the airway. In these cases, the administration of antigen is known to increase the resting tension of sensitized smooth muscle, affecting both maximum active tension (ATmax) and maximum rate of tension development ( $d T / d t)$. On this basis, it is possible to assume that the mechanical, so-called "peristal- tic", activity of the trachea is related to airway hyperactivity observed in asthma. ${ }^{15}$

Chen, $\mathrm{et} \mathrm{al} .{ }^{3}$ noted that ketamine caused a brief and mild relaxation and counteracted the spasmogenic effects of histamine on isolated tracheal chains. In isolated perfused lungs ketamine increased the basal flow rate of perfusion fluid, while in the intact guinea pigs it delayed the onset of dyspnoea, when exposed to histamine aerosol. Thus they concluded that the beneficial effects of ketamine in asthmatic patients were due to nonspecific inhibitory effects on the tracheobronchial tree.

Based also on observations made on guinea pig tracheal chains, Lundy and collaborators ${ }^{4}$ determined that ketamine possessed a direct relaxant effect on tracheal smooth muscle and antagonized the spasmogenic effects of adrenaline. They noted, however, that relaxation of tracheal chains occurred in a dose-related manner. We failed to confirm this in the airway muscle of normal guinea pigs challenged with histamine, though the range of dosages which we used was smaller than those used by Lundy, et $a l .{ }^{4}$ who challenged their preparations with carbachol.

More recently, Wanna and Gergis, ${ }^{16}$ using acute preparations of guinea pig tracheal smooth muscle, noted that procaine produced a more pronounced relaxation of histamine induced contracture than that produced by either lidocaine or ketamine. They also failed to elicit a dose-related response with the latter two drugs.

Although ketamine may be an innocuous anaesthetic agent in asthmatic patients, ${ }^{2,6.17}$ it appears from our studies that it has a mild direct bronchorelaxant effect, but certainly not one comparable to that produced by halothane. Moreover, based on its mild histamine blocking effect and its failure either to prevent or to ameliorate an anaphylactoid reaction, its role in the treatment of asthma is in doubt. However, the use of ketamine for induction of anaesthesia in asthmatic patients, as recommended by Corssen, et al., ${ }^{12}$ certainly appears warranted.

\section{REFERENCES}

I. Huher, F.C., Jr., Reves, J.G., Gutilerez, J. \& CoRssEn, G. Ketamine: its effect on airway resistance in man. South. Med. J. 65: 1176-1180 (1972).

2. Corssen, G., Gutierrez, J., Reves, J.G. \& Huber, F.C., JR. Ketamine in the anesthetic management of asthmatic patients. Anesth. Analg. 5/: 588-596(1972).

3. CHEN, C.F., et al. Effect of ketamine on the 
tracheobronchial trees of guinea pigs. J. Formosan Med. Assoc. 75: 456 (1976).

4. Lundy. P.M., Guwdi.y. C.W. \& COLhoun, E.H. Tracheal smooth muscle relaxant effect of ketamine. Brit. J. Anaesth. 46: 333-336 (1976).

5. Soumrado, I.F. \& DickleY, D.W. Effect of antigen challenge on sensitized guinea pig trachea. Resp. Physiol. 27: 241-245 (1976).

6. Corssten, G. \& Domino. E.F. Dissociative anesthesia: further pharmacologic studies and first clinical experience with the phencyclidine derivative CI-581. Anesth. Analg 45: 29-40 (1966)

7. Baraka, A., Harrison, T. \& Kachachi, T, Catecholamine levels after ketamine anesthesia. Anesth. Analg. 52: 198-200 (1973).

8. Stone. D.J., SARKar, T.K. \& Keltz, H. Effect of adrenergic stimulation and inhibition of human airways. J. Appl. Physiol. 34: 624-627 (1973).

9. ChodofF, P. Evidence for central adrenergic action of ketamine. Anesth. Analg. 5t: 247-257 (1972).

10. KL.IDE, A.M. \& Aviado. D.M. Mechanism for the reduction in pulmonary resistance induced by halothane. J. Pharmacol. Exp. Ther. 158: 28-35 (1967).
11. Colgan. F.I. Performance of lungs and bronchi during inhalation anesthesia. Anesthesiology 26: 778-785 (1965).

12. Savagl. T.M., Colvin. M.P., Wlaver. J.M., Bond, C., Drake, J. \& INNIS. R. A comparison of some cardiorespiratory effects of althesin and ketamine when used for induction of anaesthesia in patients with cardiac disease. Brit. J. Anaesth. 48: 1071-1081 (1976).

13. Gold, M.I. \& HELRICH, M. Mechanics of breathing during anesthesia. 2. The influence of airway adequacy. Anesthesiology 26: 778-785 (1965).

14. Patterson, R.W., Sullivan. S.F., Malm, J.R., Bownan, F.O.,JR. \& Papplir. E.M. The effect of halothane on human airway mechanics. Anesthesiology 29: 900-907 (1968).

15. REED. C.E. The pathogenesis of asthma. Med. Clin. N. Amer. 58: 55-63(1974)

16. WANNA. H.T.\& GtrGIS. S.D. Procaine, lidocaine, and ketamine inhibit histamine-induced contracture of guinea pig tracheal muscle in virro. Anesth. Analg. 57: 25-27 (1978).

17. GoLD. M.I. Anesthesia for the asthmatic patient. Anesth. Analg. 49: 881-888 (1970).

RéSUMÉ

Les auteurs ont déterminé la réponse contractile maxima à l'administration d'histamine, ainsi que le relâchement musculaire lisse de repos au niveau des voies aériennes. Le travail a été effectué sur des montages de trachées isolées de cobayes sains et asthmatiques. Les modifications amenées par la kétamine et l'halothane ont ensuite été étudiées. La concentration de kétamine optimale était de $10 \mu \mathrm{g} / \mathrm{ml}$. Cette dose atténuait la contraction réflexe maximale à I'histamine et produisait le plus grand relâchement au niveau de la préparation trachéale; cependant, elle était impuissante à prévenir la réponse anaphylactique (Schultz-Dalc) lorsqu'un antigène (albumine à $1 \%$ ) était ajouté à la solution baignant les montages de trachées provenant de cobayes rendus asthmatiques. L'halothane abolissait toute réponse à l'administration d'histamine el prévenait la réaction de Schultz-Dale au niveau du muscle lisse des cobayes rendus asthmatiques. 